\title{
Time for more effective masks?
}

- Cite as: CMAJ 2021 February 16;193:E258. doi: 10.1503/cmaj.1095920

Posted on cmajnews.com on January 29, 2021

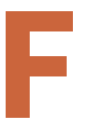
or months now, most Canadians have been following public health recommendations to wear nonmedical masks to protect themselves and others against severe acute respiratory syndrome coronavirus 2. But with the emergence of more transmissible variants of the virus, some experts are questioning whether current mask recommendations go far enough.

"Cloth masks, especially homemade ones, were supposed to be a stopgap measure" until countries could ramp up production of protective equipment, wrote Zeynep Tufecki and Jeremy Howard in The Atlantic. "Why are so many of us still wearing them?"

According to Zeynep and Tufecki, wearing nonmedical masks was "much better than nothing" when countries faced shortages of higher grade N95 respirators and equivalents. But they argued there are "better possibilities now," noting that Taiwan and Hong Kong have increased production to distribute high-quality masks to their populations.

Public health experts and physicians have raised similar concerns on social media, rallying around the hashtag \#bettermasks. "A fabric mask is a lot better than no mask, but we may need to step up our mask game if contagious COVID variants start to spread widely," tweeted Dr. Tom Frieden, former director of the U.S. Centers for Disease Control.

According to Joseph Allen of Harvard University's T.H. Chan School of Public Health, governments could also offer clearer guidance on separating good quality masks from the sea of unregulated and sometimes counterfeit options.

Most masks provide some level of protection but, depending on fabric and fit, their efficacy can vary widely from blocking less than $10 \%$ of virus particles to nearly $100 \%$. One study showed N95 respirators and equivalents filtered $80 \%-$

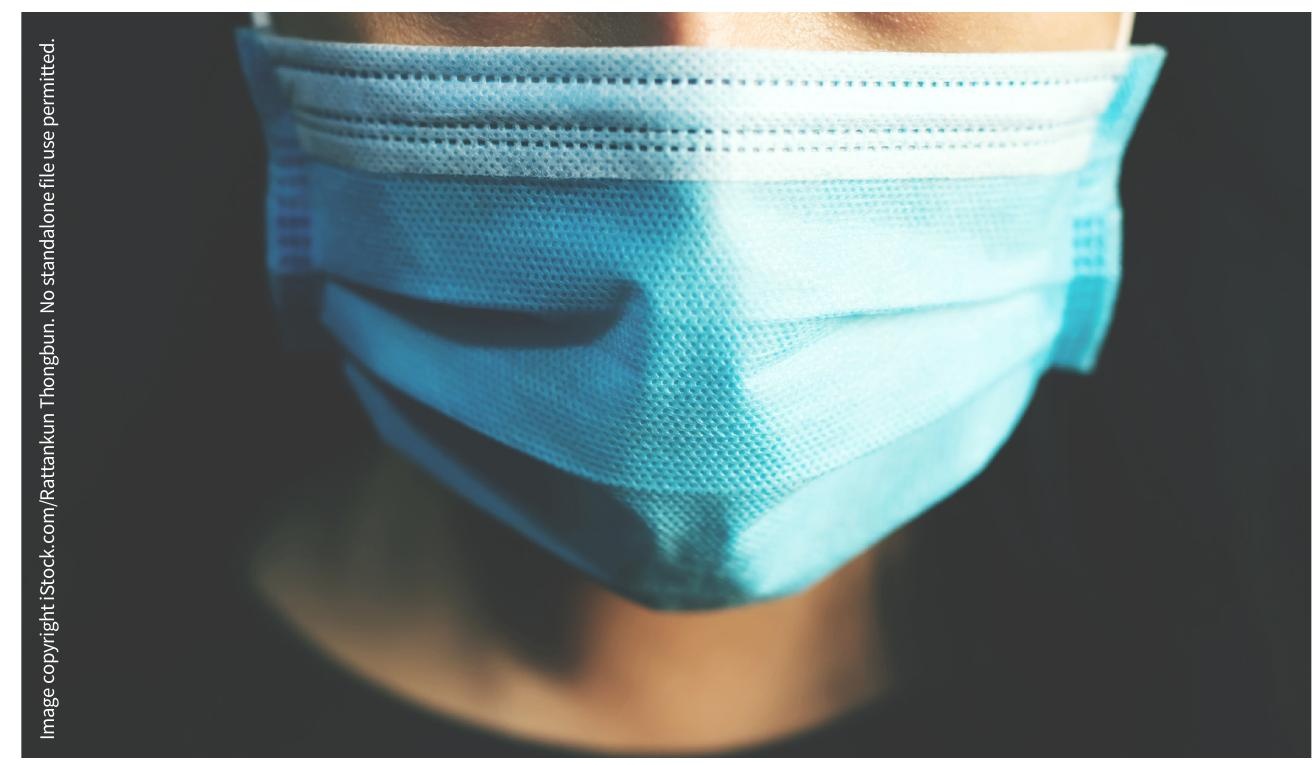

Canada and the United States have lagged on securing supplies of high-quality masks for their populations while other countries are distributing and mandating them widely.

$90 \%$ of virus droplets and aerosols, while three-ply surgical masks blocked about $50 \%$ and cloth masks blocked 20\%-40\%.

In Europe, increasing concern about the spread of new coronavirus variants recently prompted several countries to mandate the widespread use of high-quality masks and respirators that block $90 \%-95 \%$ of particles.

Health officials in the United States and Canada have taken a more conservative stance, possibly because of ongoing supply issues. In the U.S., Dr. Anthony Fauci recently suggested that wearing a cloth mask over a surgical mask "might be better than a single mask," although he later backtracked.

In Canada, Chief Public Health Officer Dr. Theresa Tam suggested in November that Canadians should start wearing face coverings made of three layers, with one layer being a filter.

According to a spokesperson for Health Canada and the Public Health Agency of Canada, federal officials are aware of the recommendations coming out of Europe and will "consider what additional measures may be needed to address emerging variant viral strains."

In the meantime, the government will continue to "reinforce the importance of consistently wearing well-fitting masks." With the right fit, at least one study suggests it's possible for the type of nonmedical mask recommended by Health Canada to filter $90 \%$ of virus particles.

However, the federal spokesperson did not answer why Canada still doesn't have enough supplies of N95 respirators or other medical-grade masks for the general public.

\section{Diana Duong, CMAJ}

Content licence: This is an Open Access article distributed in accordance with the terms of the Creative Commons Attribution (CC BY-NC-ND 4.0) licence, which permits use, distribution and reproduction in any medium, provided that the original publication is properly cited, the use is noncommercial (i.e., research or educational use), and no modifications or adaptations are made. See: https://creativecommons.org/ licenses/by-nc-nd/4.0/ 